Article

\title{
Carbon Footprint Planning: Quantifying Local and State Mitigation Opportunities for 700 California Cities
}

\author{
Christopher M. Jones ${ }^{1, *}$, Stephen M. Wheeler ${ }^{2}$ and Daniel M. Kammen ${ }^{1,3,4}$ \\ ${ }^{1}$ Renewable and Appropriate Energy Laboratory, Energy and Resources Group, University of California - Berkeley, Berke- \\ ley, CA 94720, USA; E-Mails: cmjones@berkeley.edu (C.M.J.), kammen@berkeley.edu (D.M.K.) \\ 2 Department of Human Ecology, University of California - Davis, Davis, CA 95616, USA; E-Mail: smwheeler@ucdavis.edu \\ ${ }^{3}$ Goldman School of Public Policy, University of California - Berkeley, Berkeley, CA 94720, USA \\ ${ }^{4}$ Department of Nuclear Engineering, University of California - Berkeley, Berkeley, CA 94720, USA \\ * Corresponding author
}

Received: 5 October 2017 | Accepted: 11 January 2018 | Publication: 24 April 2018

\begin{abstract}
Consumption-based greenhouse gas (GHG) emissions inventories have emerged to describe full life cycle contributions of households to climate change at country, state and increasingly city scales. Using this approach, how much carbon footprint abatement potential is within the control of local governments, and which policies hold the most potential to reduce emissions? This study quantifies the potential of local policies and programs to meet aggressive GHG reduction targets using a consumption-based, high geospatial resolution planning model for the state of California. We find that roughly $35 \%$ of all carbon footprint abatement potential statewide is from activities at least partially within the control of local governments. The study shows large variation in the size and composition of carbon footprints and abatement opportunities by $\sim 23,000$ Census block groups (i.e., neighborhood-scale within cities), 717 cities and 58 counties across the state. These data and companion online tools can help cities better understand priorities to reduce GHGs from a comprehensive, consumption-based perspective, with potential application to the full United States and internationally.
\end{abstract}

\section{Keywords}

carbon footprint; climate action plans; climate change; consumption; emissions inventory; greenhouse gas

Issue

This article is part of the issue "Urban Planning to Enable a $1.5^{\circ} \mathrm{C}$ Scenario", edited by Peter Newman (Curtin University, Australia), Aromar Revi (Indian Institute for Human Settlements, India) and Amir Bazaz (Indian Institute for Human Settlements, India).

(C) 2018 by the authors; licensee Cogitatio (Lisbon, Portugal). This article is licensed under a Creative Commons Attribution 4.0 International License (CC BY).

\section{Introduction}

Stabilizing the climate will require massive changes in systems of production and consumption (Hertwich et al., 2010), with widescale adoption of low-carbon technologies and practices for businesses and households (IPCC, 2014). To-date, local planning and policy have focused largely on production-based emissions (i.e., regulating emissions at the point they enter the atmosphere); however, there is increasing recognition of the value of a consumption-based approach to planning, considering the full life cycle of transportation, energy, food, goods and services consumed by households within communities (Erickson, Chandler, \& Lazarus, 2012). Household consumption drives demand for global economic activity and corresponding emission of greenhouse gases globally. As the closest authority to individuals and households, local governments are widely recognized as critical in changing consumer patterns, yet few studies have evaluated the potential of local government policies to reduce consumption-based greenhouse gases.

This article evaluates the potential to deeply reduce household carbon footprints through state and local policies and programs over a long timeframe (from 2010 to 
2050) for the state of California. Using a high geospatial resolution, consumption-based greenhouse planning model, we develop carbon footprint profiles and a deep carbon footprint abatement scenario for $\sim 23,000$ Census block groups, 717 cities and towns, and all 58 California counties, as well as for the state overall. We investigate the potential of urban infill, conservation, efficiency and renewable energy policies across each area of carbon footprints: transportation, energy, food, goods and services. Our exploration of the model highlights statewide potential of each intervention area and examples from cities with similar populations, but different abatement profiles. While the findings are specific to California communities, the method and perspective provided by carbon footprint planning should be useful to planners and policymakers elsewhere.

\section{Previous Efforts to Quantify GHG Abatement Potential of Cities}

Local planning to reduce greenhouse gas (GHG) emissions has become increasingly common and is now mandatory in progressive jurisdictions such as California (Bassett \& Shandas, 2010; Bedsworth \& Hanak, 2013; Boswell, Greve, \& Seale, 2012; Bulkeley, Broto, \& Edwards, 2014). Community climate action plans typically promote energy efficiency, renewable energy, more compact, transit-oriented urban development, active and public transportation, and waste and water management; however, plans typically do not quantify expected results (Boswell et al., 2012; Bulkeley et al., 2014).

A large number of policies and programs to engage residents successfully in climate action are possible. Behavioral strategies include persuasive appeals, incentives, social marketing, community-based programs and cross-sectoral approaches involving multiple strategies and stakeholders (Abrahamse, Steg, Vlek, \& Rothengatter, 2005). Many of these approaches are cost-effective and can be implemented in short timescales (Stern et al., 2016). While attempts to change household behavior often focus on changing lifestyles (e.g., driving less, or changing diets), encouraging adoption of low-carbon technology and urban planning also require important changes in human behavior. Medium and long-terms approaches are ultimately necessary to achieve deeper savings and to engender a culture of sustainability thought to be necessary to achieve and maintain long-term sustainability goals (Wheeler, 2012).

Over the past two decades an extensive literature has documented public and private approaches to engage households in energy efficiency, GHG abatement and sustainability (Abrahamse et al., 2005; Abrahamse \& Steg, 2013; Delmas, Fischlein, \& Asensio, 2013; Dietz, Gardner, Gilligan, Stern, \& Vandenbergh, 2009; Stern et al., 2016). Dietz et al. (2009) estimated a $20 \%$ reduction in direct household emissions in the U.S. within a decade, and more if a renewable energy is widely adopted. The study considers both the technical poten- tial of taking actions, and the likely number of households that can be engaged based on previously successful initiatives. Jones and Kammen (2011) approximated technical abatement potential for 26 metropolitan regions, finding $20 \%$ abatement potential at net negative cost to households for a single year. One study (Erickson, Chandler, \& Lazarus, 2012) estimated carbon footprint reduction potential of $47 \%$ by 2030 for the city of Seattle, finding that vehicles, energy, extending product life spans and low carbon diets (in that order) have the most savings potential. In contrast, Wei et al. (2013) estimated behavioral savings potential in California as $10 \%$ to $15 \%$ of statewide emissions, using a combination of technical and achievable potential, while Greenblatt (2015) roughly approximated the potential of local government action in California at $12 \mathrm{MMTCO}_{2}$ e in 2030 ( 5\% of emissions), mainly through renewable energy commitments. The present study seeks to quantify local and state carbon footprint abatement potential for all California cities and develop a model that can readily scale to the rest of the U.S., and beyond.

\section{A Consumption-Based GHG Inventory Approach}

Efforts to reduce GHG emissions depend on understanding the sources and quantities of these pollutants. Since the 1990s, researchers and institutions have developed multiple carbon accounting frameworks (Wiedmann, Chen, \& Barrett, 2015). At national and state scales, GHG inventories typically focus on large producers, tabulating the emissions generated by energy utilities, major industries, and other economic sectors using a combination of reported and modeled data. This information then informs large-scale GHG mitigation policies, which often focus on broad forms of regulation such as vehicle and appliance efficiency standards and utility portfolio standards for renewable energy. Increasingly, cities and urban regions create such sector-specific GHG inventories as well; however, these typically exclude emissions associated with the production of goods, food and services consumed within a jurisdiction's geographic borders, but produced elsewhere.

In an effort to provide a more comprehensive accounting framework for the U.S., ICLEI-USA (ICLEI, 2012) developed the U.S. Community Protocol for Accounting and Reporting of Greenhouse Gas Emissions (ICLEI Community Protocol). In addition to the five required sources in the global community protocol, the U.S. protocol encourages inclusion of full life cycle accounting of major sources of emissions, while a consumptionbased inventory is "strongly encouraged" (ICLEI, 2012, p.16). Consumption-based inventories are not intended to replace the traditional method, which is required under the protocol, but rather to serve as an additional 'story' or lens to view emissions. Sources included in the required approach are thought to be more within the direct control of municipal governments, while the consumption-based approach provides the full carbon 
footprint of residents. Household carbon footprint data from a previous study (Jones \& Kammen, 2014) are freely available for any U.S. zip code, city or county (http://coolclimate.org/data), and a growing list of cities and regions have included the data in their climate action plans, including New York City (Dickinson, Khan, \& Amar, 2013) and the San Francisco Bay Area (BAAQMD, 2017).

A consumption-based emissions inventory (CBEI) focuses on the economic activities of residents, allocating all emissions to final demand (mostly consumers, but in some cases government activities and business capital expenditures as well), regardless of where emissions are released into the atmosphere throughout supply chains (Ramaswami \& Chavez, 2013; Wiedmann et al., 2015). Household carbon footprints are calculated with the assumption that all global economic activity is at the service of households and, therefore, all life cycle emissions associated with the production, use and disposal of goods and services are included in household carbon footprints. For example, if a factory in China produces a computer that is purchased by a California household, then all emissions related to the mining, refining, manufacturing, shipping and trade of the computer are allocated to the California household, not the Chinese company. Conversely, emissions associated with a product made in California, but consumed in China, would theoretically correspond to the carbon footprint of the Chinese household. Unlike traditional inventories, which include emissions from local businesses, a consumption-based inventory allocates all supply chain emissions to households, regardless of where those emissions originate. Household carbon footprints include emissions associated with all household consumption, including transportation, energy, housing, water, waste, food, goods and service. Any 'carbon footprint assessment' that does not include at least all household economic activities is not technically a household carbon footprint. Summing up, the carbon footprints of all residents in a local jurisdiction is the consumption-based GHG inventory of that location.

Both territorial and consumption-based methods are fully comprehensive-if all countries and regions of the planet accounted for emissions using both approaches, total emissions globally would be the same using either method, but their results can vary greatly for local communities. The consumption-based approach provides a more comprehensive lens by which to view the responsibility of any locality, and suggests a different set of GHG mitigation opportunities (Larsen \& Hertwich, 2009). Meanwhile, some researchers (e.g., Lazarus, Chandler, \& Erickson, 2013; Ramaswami \& Chavez, 2013) take a hybrid approach, seeking to include consumption to some extent but to emphasize those forms of emissions that local governments can control. Such approaches may have practical benefits but risk being less comprehensive.

A growing list of studies from individual locations demonstrates that household carbon footprints and corresponding GHG mitigation opportunities vary dramati- cally by location. Consumption-based inventories have been conducted for thousands of cities in dozens of countries, including 434 municipalities in the U.K. (Minx et al., 2013), 177 regions in 27 European countries (Ivanova et al., 2017), over a dozen cities in China (Mi et al., 2016), three neighborhoods in Pakistan (Adnan, Safeer, \& Rashid, 2018) and multiple studies in Australia (Lenzen \& Peters, 2010; Wiedmann et al., 2015). Jones and Kammen (2014) calculated carbon footprints for all $(>30,000)$ populated U.S. zip codes, cities, counties and states, finding considerable differences between locations. For example, electricity accounts for only $5 \%$ of household carbon footprints on average in California, but for over $30 \%$ in many other parts of the United States. Some studies have noted the distinction between 'consumer cites' and 'producer cities' (Ramaswami \& Chavez, 2013; Sudmant, Gouldson, Millward-Hopkins, Scott, \& Barrett, 2017), finding residential and higher income cities tend to have higher consumption-based emissions, compared to higher production-based emissions in industrial cities. Such heterogeneity between locations suggests that local climate planning requires a nuanced, place-based application of strategies that consider the unique GHG mitigation opportunities of each location. As is shown in the current study, carbon footprints vary dramatically within city boundaries at neighborhood scales as well. Models that estimate carbon footprints and projections for all cities in a state (or country), ideally at fine geospatial resolution, should be particularly useful for this nuanced approach to climate planning. Policies and programs will have very different outcomes for populations within and between jurisdictions.

Consumption-based inventory methods arose partly due to the realization that a large proportion of emissions that a jurisdiction is responsible for occur outside its borders. For example, Weber and Matthews (2008) estimated that $30 \%$ of total U.S. GHG impact in 2004 arose because of imported household purchases. Feng, Hubacek, Sun and Liu (2014) found that between 48 and $70 \%$ of emissions associated with four Chinese megacities occurred beyond their borders. Larsen and Hertwich (2009) found that about $90 \%$ of the total carbon footprint of Trondheim, Norway, was indirect, resulting from upstream sources that should be considered within municipal decision-making. Minx et al. (2013) found that 90\% of the British communities they studied imported emissions on net. In a study of eight U.S. cities, Hillman and Ramaswami (2010) found that trans-boundary activities (import of food, water, energy, and building materials, plus air travel emissions) produced $47 \%$ more emissions than shown by the territorial GHG inventories performed by the cities. Such studies imply that local jurisdictions using a territorial method for estimating emissions may be seriously underestimating their own contribution to global warming.

Consumption-based GHG emissions mapping efforts are beginning to develop useful recommendations for local climate action planning. Barrett, Minx, and Paul 
(2007) used a regional analysis of ecological footprints in Scotland to develop recommendations on improving land use mix, housing energy efficiency, community garden locations, sustainable eating programs, and waste management strategies. In their consumptionbased inventory of Melbourne, Wiedmann, Chen and Barrett (2015) found that local carbon footprint data can help prioritize locations for building retrofit programs and microgrids. In a consumption-based modeling of future emissions for the Seattle region, Erickson, Chandler and Lazarus (2012) found that, unless checked, future increases in consumption would offset decreases in transportation-related emissions, and recommended behavioral measures to reduce meat consumption and purchase of new home furnishings and clothing. However, they admitted that few policy mechanisms exist for such reductions as of yet. Such analyses suggest new priorities for local climate change mitigation planning.

The primary objective of climate action plans is to identify the opportunities with the most potential to reduce greenhouse gases emissions from local activities. Both production-based and consumption-based inventory methods are necessary to fully capture these opportunities and the weaknesses and strengths of each approach complement each other. Production-based accounting is easier to track over time based on local policy outcomes; while the consumption-based approach is more appropriate for engaging households directly in climate action. A simple, free method of identifying consumption-based emissions and abatement potential for all jurisdictions, along with accompanying carbon management tools for households (http://coolclimate.org/ calculator), provides a more comprehensive set of GHG mitigation opportunities for communities.

\section{Estimating Carbon Footprints and Abatement Potential of California Locations}

This article develops a consumption-based GHG inventory of all populated Census block groups, cities, and counties in California, and a deep carbon footprint reduction planning scenario to the year 2050, based on changes in population (urban infill), technology, conservation and adoption of renewable energy. It is the first study to estimate carbon footprints at such fine geospatial resolution-essentially at neighborhood scale in urbanized portions of the state. Our CBEI method has been described extensively in previous publications (Jones \& Kammen, 2011, 2014, 2015). It is also described in Appendix R of the ICLEI GHG Protocol (ICLEI, 2012), which planners use to develop community GHG inventories in the U.S. Here we present a brief overview of the methodology for interested readers.

The basic approach is to calculate average household carbon footprints for each U.S. Census block group and then create population-weighted averages for each city, county, and the state as a whole. The average household's consumption of energy, transportation fu- els, water, waste, construction, goods and services is estimated-using methods described below-and then multiplied by GHG emission factors and summed for the total household carbon footprint. Multiplying average household carbon footprints by the total number of households in a given location produces a consumptionbased GHG inventory of that locale. Emissions from all businesses, whether global or local, are allocated to products consumed by households. We have excluded municipal government emissions, which jurisdictions typically already track and are relatively low (Erickson, Allaway, Lazarus, \& Stanton, 2012).

We obtained local consumption data where possible, including electricity and natural gas consumption by zip code, average fuel economy of vehicles by county, public transit energy consumption by county and local price adjustments for metropolitan areas. Where detailed local information was not available, we developed econometric models of household consumption using local subsamples of the National Household Travel Survey (NHTS) (Oak Ridge National Laboratory, 2013), the Residential Energy Consumption Survey (RECS) (U.S. Energy Information Administration, 2009), and the Consumer Expenditures Survey (Bureau of Labor Statistics, 2013). We estimated motor vehicle miles traveled (VMT) based on vehicle ownership, household size, income, number of workers, and population density for each subsample in the NHTS (San Francisco, San Jose, Los Angeles, Riverside, Sacramento, San Diego areas, plus other California locations). We estimated air travel as a function of income, and public transit use using county-level information from the National Transit Database. Actual electricity and natural gas consumption by zip codes was obtained from the largest electric utilities (PG\&E, SDG\&E and SCE) and local utilities in the San Francisco Bay Area (Jones \& Kammen, 2015). Where utility data were not available, we modeled demand for electricity, natural gas and other heating fuels using demographic information, physical characteristics of homes and weather (heating and cooling degree days) in RECS. We approximated household consumption of goods and services using income and household size, the two variables with the most explanatory power in the Consumer Expenditures Survey. Diets were derived from USDA (2015), the Consumer Expenditures Survey (Bureau of Labor Statistics, 2013) and the Cost of Living Index (C2ER, 2014). Other sources of consumption include water, waste and home construction. See Jones and Kammen $(2011,2014,2015)$ for further details on consumption models and emission factors.

The next step after obtaining a consumption-based inventory for all block groups in 2010 was to project these emissions into the future based on a deep carbon footprint abatement policy scenario. There are four types of interventions. Urban infill policies adjust the population of each block group by putting more new development in lower carbon footprint locations and adjusting the size of homes in those locations. Conservation strategies reduce the amount of consumption for each household 
(e.g., driving less or turning down thermostats in summer). Efficiency strategies involve the purchase of highly efficient technology to use less energy or fuel. Finally, renewable energy strategies replace fossil fuels with renewable sources of energy. Each major source of carbon footprints (vehicles, food, energy, etc.) is associated with each of the four types of mitigation strategies: infill, conservation, efficiency, renewables. We call this combination of carbon footprint source and mitigation strategy a 'policy intervention area'. Intervention areas could conceivably contain multiple specific policies.

Table 1 summarizes the adoption rates of intervention areas in the year 2050. Rates are expressed as a percentage of full adoption by the year 2050. Under this scenario, by $2050,80 \%$ of new homes would be built in urban infill locations; homes would be $25 \%$ smaller; vehicle miles and air miles would be reduced by $25 \%$; demand for energy services would be reduced by $20 \%$; $25 \%$ of consumption would be shifted from high carbon goods to services; $20 \%$ of households would eat a low-carbon, plant-based diet; and waste and water consumption would be cut by $25 \%$. Highly efficient technology would reduce end use energy consumption by between $30 \%$ and $60 \%$, depending on the technology. $50 \%$ of household vehicles would be electric, while the other $50 \%$ would average 50 miles per gallon. Energy would be produced from mainly renewable sources, ranging from $30 \%$ for the remaining transportation fuels to $100 \%$ for electricity. All home heating would be from efficient electric heat pumps, with mandatory phase in starting in the late 2020s. Total assumed adoption rates for the year 2050 for each intervention area are shown in the final column of Table 1. These rates were chosen based on evaluation of several studies producing scenarios to achieve California's 2030 and 2050 GHG targets (Jones \& Kammen, 2018; Greenblatt, 2015; Wei et al., 2013; Williams et al., 2012). Adoption would be accomplished through a combination of existing and new policies.

The policy intervention areas are further separated into 'state only' and 'local' adoption rates; these are estimates of the contribution of each jurisdiction in meeting targets. 'Local' is intended to mean at least partially within local control. For example, the state of California sets targets for land use, but implementation is left to local jurisdictions; we would consider this 'local' in our framework. We make the following assumptions (see Table 1): urban infill and conservation (e.g., programs to reduce energy or meat consumption) are almost entirely in the domain of communities; energy efficiency (e.g., energy efficient equipment and building envelopes) for new construction requires state policy to set targets, and local adoption (1:1 state vs. local split), while retrofits require more community level implementation (1:2 state vs. local split); industrial, agricultural and airline efficiency are not within local control, but the commercial sector (e.g., green business programs) is evenly split (1:1 state vs. lo-

Table 1. Adoption rates of intervention areas in the year 2050.

\begin{tabular}{|c|c|c|c|c|c|}
\hline & & BAU & State Only & Local & Total \\
\hline \multirow[t]{2}{*}{ Urban Infill } & New Growth in Low Carbon Zones & $10 \%$ & $0 \%$ & $70 \%$ & $80 \%$ \\
\hline & Smaller Home Sizes (new) & $0 \%$ & $0 \%$ & $25 \%$ & $25 \%$ \\
\hline \multirow[t]{7}{*}{ Conservation } & VMT Reduction & $0 \%$ & $5 \%$ & $20 \%$ & $25 \%$ \\
\hline & Air Travel Reduction & $0 \%$ & $5 \%$ & $20 \%$ & $25 \%$ \\
\hline & Energy Conservation & $0 \%$ & $0 \%$ & $20 \%$ & $20 \%$ \\
\hline & Shift Consumption & $0 \%$ & $0 \%$ & $25 \%$ & $25 \%$ \\
\hline & Healthy Diets & $0 \%$ & $0 \%$ & $20 \%$ & $20 \%$ \\
\hline & Waste Conservation & $0 \%$ & $0 \%$ & $30 \%$ & $30 \%$ \\
\hline & Water Conservation & $0 \%$ & $0 \%$ & $30 \%$ & $30 \%$ \\
\hline \multirow[t]{8}{*}{ Efficiency } & 50+ MPG Vehicles & $10 \%$ & $35 \%$ & $5 \%$ & $50 \%$ \\
\hline & Energy Efficiency (new) & $10 \%$ & $20 \%$ & $20 \%$ & $50 \%$ \\
\hline & Energy Efficiency (existing) & $0 \%$ & $20 \%$ & $40 \%$ & $60 \%$ \\
\hline & Air Travel Efficiency & $0 \%$ & $30 \%$ & $0 \%$ & $30 \%$ \\
\hline & Commercial Efficiency & $10 \%$ & $25 \%$ & $25 \%$ & $60 \%$ \\
\hline & Waste Efficiency & $0 \%$ & $0 \%$ & $40 \%$ & $40 \%$ \\
\hline & Industrial Efficiency & $10 \%$ & $50 \%$ & $0 \%$ & $60 \%$ \\
\hline & Agricultural Efficiency & $5 \%$ & $50 \%$ & $0 \%$ & $55 \%$ \\
\hline \multirow[t]{4}{*}{ Renewable Energy } & Electric Vehicles & $5 \%$ & $30 \%$ & $15 \%$ & $50 \%$ \\
\hline & Zero Carbon Fuels & $0 \%$ & $30 \%$ & $0 \%$ & $30 \%$ \\
\hline & Low Carbon Electricity & $35 \%$ & $25 \%$ & $40 \%$ & $100 \%$ \\
\hline & Heating Electrification & $0 \%$ & $0 \%$ & $100 \%$ & $100 \%$ \\
\hline
\end{tabular}

Notes: Adoption rates of policy intervention areas expressed as a percentage of full adoption in the year 2050 (e.g., VMT will be reduced by $25 \%$, and $50 \%$ of vehicles will be electric by 2050 ). Adoption rates under BAU, state only policies, local interventions and total (sum of each jurisdiction) is expressed in columns. 
cal split); communities have more control over electric vehicle adoption (e.g., charging infrastructure and social marketing) (2:1 state vs. local split) than promoting high efficiency vehicles (e.g., through social marketing) (7:1 state vs. local split); most communities can switch to community choice energy (local procurement of renewable electricity contracts) with $100 \%$ adoption, but not all (5:8 state vs. local split); heating electrification is entirely within local control (assuming a supportive policy environment allowing this). All results are compared to expected business as usual (BAU) in 2050. We are not aware of an accepted definition of local control or estimates in the literature; this distinction between state only and (at least some) local control is our best guess estimate and our results must be considered in the context of the model.

We adjust changes in population (urban infill), consumption, technology and renewable energy based on Table 1 and an assumed adoption curve for each measure (set at $8 \%$ by $2020,60 \%$ by $2030,85 \%$ by 2040 and $100 \%$ of the maximum rate by 2050 ).

\section{The Spatial Distribution of Household Carbon Footprints}

Our study presents a high geospatial resolution, consumption-based GHG inventory of all California Census block groups, cities and counties, and for the state overall. Household sources that are typically included in territorial inventories account for, on average, only $30 \%$ of carbon footprints, including gasoline $(20 \%)$, electricity $(5 \%)$, natural gas $(4 \%)$, other fuels $(1 \%)$, and waste (1\%). About $70 \%$ are indirect sources, including life cycle emissions from food (19\%), goods (17\%), services (15\%), transportation fuels (5\%), vehicle maintenance (3), air travel (4\%), home construction (3\%), household fuels
(3\%) and water (2\%). Thus, community GHG inventories that do not include consumption exclude the vast majority of emissions related to household behavior and miss important mitigation opportunities.

The total carbon footprint for the average California household is 44 metric tons of $\mathrm{CO}_{2}$ equivalent gases per year $\left(\mathrm{tCO}_{2} \mathrm{e}\right)$. When multiplied by all households in the state, the total is $24 \%$ higher than the State of California's territorial inventory: $550 \mathrm{MMTCO}_{2} \mathrm{e}$ from a consumptionbased approach vs. $445 \mathrm{MMTCO}_{2}$ e from the state's 2010 GHG inventory. At local scales, the difference can be much larger. For example, our consumption-based inventory is 35\% higher than the San Francisco Bay Area GHG inventory, with food contributing the largest differences: only $2 \%$ in the territorial approach vs. $20 \%$ in the consumptionbased approach (Jones \& Kammen, 2015). Other research has shown that in primarily residential communities, a consumption-based inventory can be up to three times larger than a production-based inventory (Chavez \& Ramaswami, 2013). For most cities, if GHG emissions are only reduced from direct sources, an increasing share of carbon footprints will be embodied in consumption, essentially exporting those emissions to other places.

The size and composition of carbon footprints varies greatly between and within population centers throughout the state, with important implications for planning. When viewed at high spatial resolution (Census block groups), cities show large differences between neighborhoods in all aspects of carbon footprints (transportation, energy, food, goods and services). Figure 2 is a map of total household carbon footprints by block group in the urban core of the San Francisco Bay Area. The lowest average carbon footprint of any Census block group in the Bay Area is $15 \mathrm{tCO}_{2} \mathrm{e}$ per household (about one third of the statewide average) and the highest is $104 \mathrm{tCO}_{2} \mathrm{e}$ (a difference of $7 x$ ). While the urban core cities of San Francisco
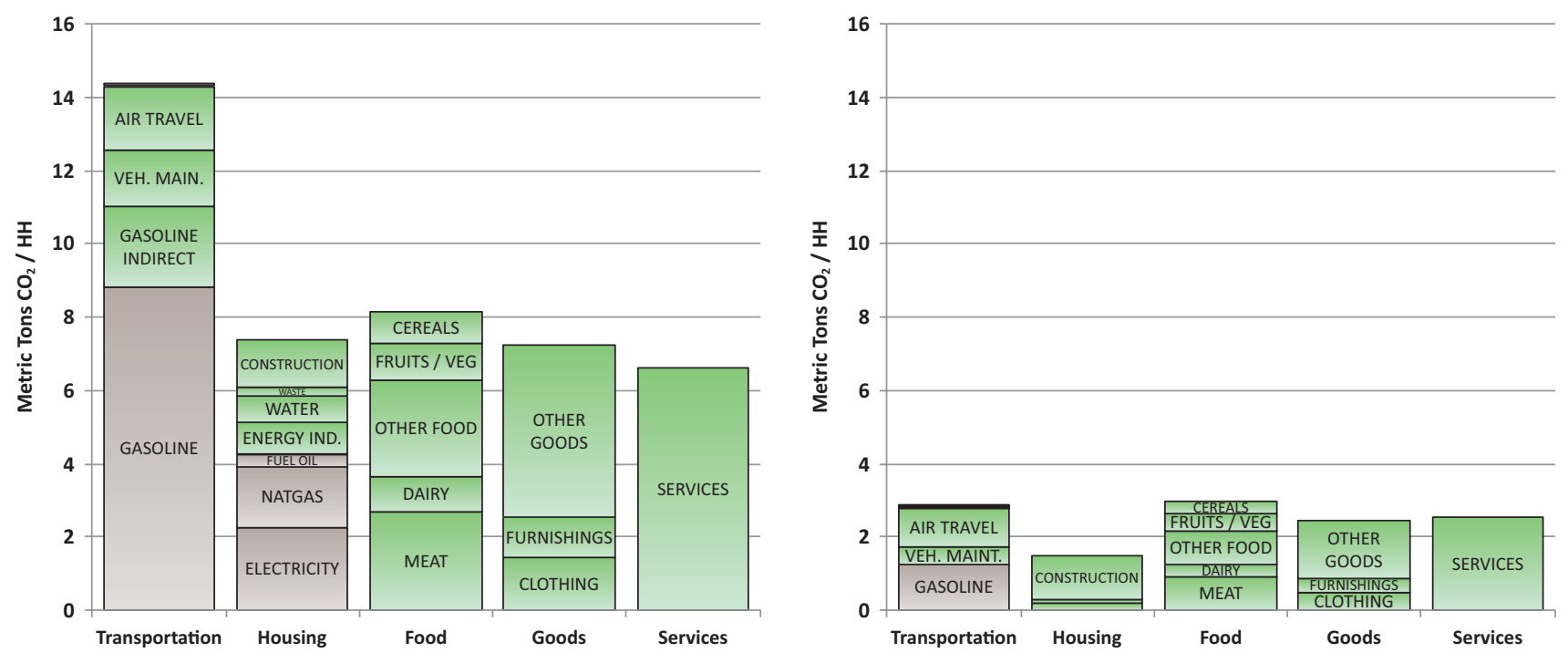

Figure 1. Carbon footprint of average California household in 2010 and 2050 under deep GHG abatement. Green colored bars are indirect emissions from the life cycle of products and services that are not typically covered in production-based inventories (unless produced locally). 


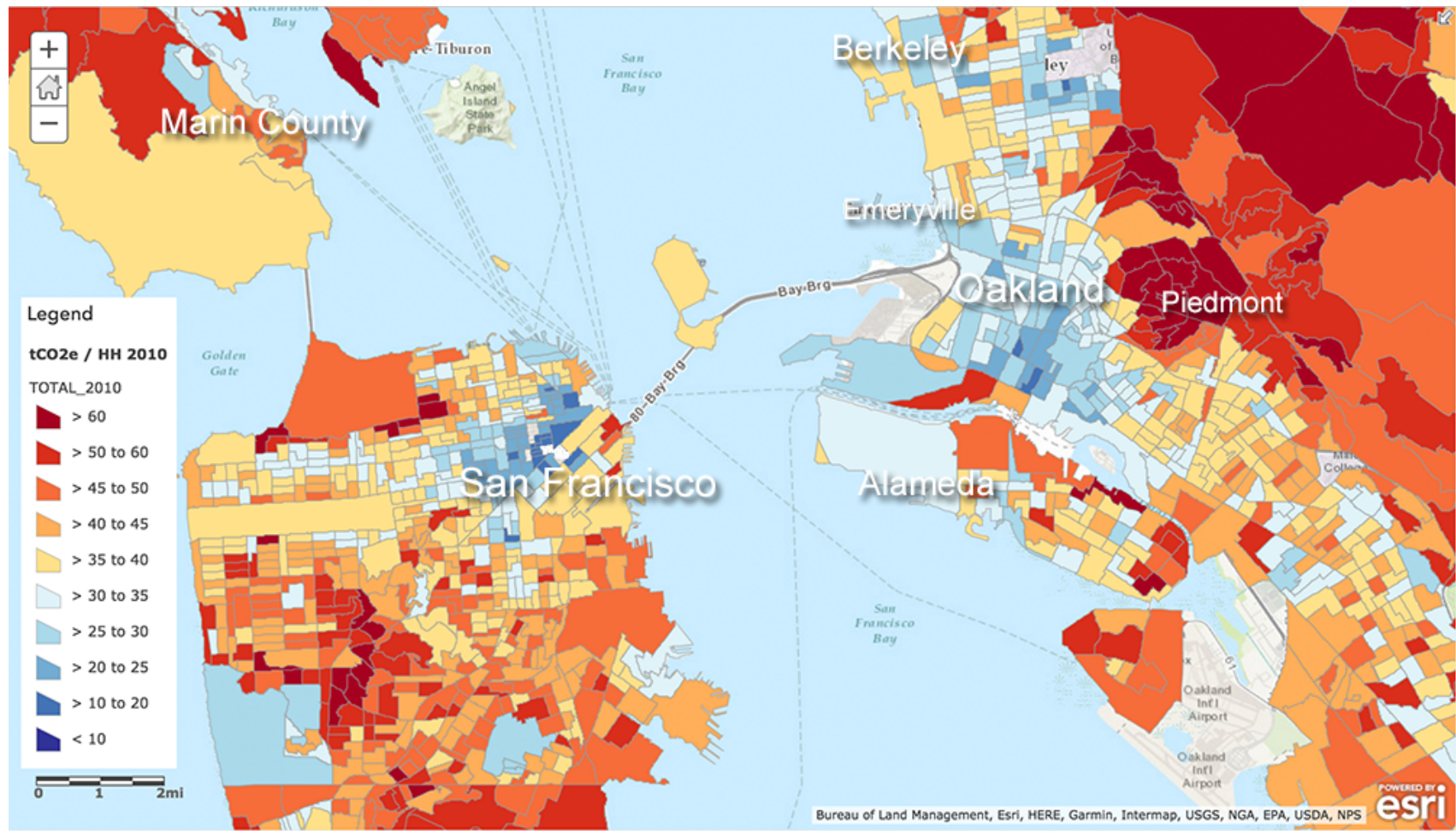

Figure 2. Carbon footprint of S.F. Bay Area households by Census block group.

and Oakland have among the lowest carbon footprint neighborhoods, as well as low emissions overall (40 and $38 \mathrm{tCO}_{2} \mathrm{e}$, respectively), they also contain some of the highest carbon footprint neighborhoods in the state.

\section{Statewide Carbon Footprint Abatement Potential}

Ultimately, households have control over their consumption and associated GHG emissions. Local and state governments seeking to influence household consumption may choose from four types of interventions (Raupach et al., 2007): population (urban infill), conservation (consumption), efficiency (energy intensity), and renewable energy (carbon intensity). Each of these intervention types can be applied to different aspects of household carbon footprints: transportation, energy, food, and consumption of goods and service. Different policies and intervention strategies are necessary depending on the intervention type and consumption category. Table 2 provides examples of interventions in each area.

Table 2. Climate policy intervention areas by major category of household carbon footprints.

\begin{tabular}{|c|c|c|c|c|}
\hline & Urban Infill & Conservation & Efficiency & Renewable Energy \\
\hline Transportation & $\begin{array}{l}\text { - Shorter travel } \\
\text { distances }\end{array}$ & $\begin{array}{l}\text { - Reduce VMT (transit, } \\
\text { demand-side } \\
\text { management) }\end{array}$ & $\begin{array}{l}\text { - Fuel economy (or } \\
\text { efficiency) standards }\end{array}$ & $\begin{array}{l}\text { - Low carbon fuel } \\
\text { standards } \\
\text { - Electric vehicles }\end{array}$ \\
\hline Energy & $\begin{array}{l}\text { - Smaller homes } \\
\text { - Adjusting } \\
\text { thermostats }\end{array}$ & $\begin{array}{l}\text { - Turning off lights } \\
\text { - Energy efficiency } \\
\text { standards }\end{array}$ & $\begin{array}{l}\text { - Home retrofits } \\
\text { - Heating Electrification }\end{array}$ & - Renewable energy \\
\hline Food/Diets & $\begin{array}{l}\text { - Smaller household } \\
\text { sizes } \\
\text { - Urban agriculture }\end{array}$ & $\begin{array}{l}\text { - Eating less } \\
\text { - Reducing food waste } \\
\text { - Reducing meat, dairy } \\
\text { \& processed foods }\end{array}$ & $\begin{array}{l}\text { Buy organic, local, } \\
\text { efficiently produced } \\
\text { food }\end{array}$ & $\begin{array}{l}\text { - Support farmers } \\
\text { that have methane } \\
\text { capture or } \\
\text { renewable energy }\end{array}$ \\
\hline $\begin{array}{l}\text { Consumption } \\
\& \text { Waste }\end{array}$ & $\begin{array}{l}\text { - Smaller household } \\
\text { sizes } \\
\text { - Smaller homes } \\
\text { - Higher cost of living }\end{array}$ & $\begin{array}{l}\text { - Improve conservation in } \\
\text { commercial sector } \\
\text { - Shift consumption to } \\
\text { more services } \\
\text { - Recycling }\end{array}$ & $\begin{array}{l}\text { - Improve efficiency of } \\
\text { local services } \\
\text { - Encourage local } \\
\text { services }\end{array}$ & $\begin{array}{l}\text { - Electrification and } \\
\text { renewable energy in } \\
\text { commercial sector }\end{array}$ \\
\hline
\end{tabular}

Note: Examples of state and local policies are included in each box. 
Baseline GHG emissions, local abatement potential of each intervention area, cumulative state only policies, and remaining carbon footprints under the deep GHG abatement scenario are shown in Figure 3. In 2010, transportation was the largest source of emissions, followed by food, goods, services, and housing. If all policies are successfully applied, transportation and housing emissions are cut dramatically (70\% and $90 \%$, respectively), leaving food as the largest source of carbon footprints in 2050. Electric vehicles, commercial efficiency, high efficiency vehicles, urban infill, renewable energy, heating electrification, VMT reduction, and healthy diets are all large sources of abatement (discussed in detail below). The combination of all state and local policies reduces carbon footprints 38\% below 2010 levels in 2030, and $65 \%$ below by 2050 . Further abatement does not appear feasible without similar GHG abatement in imports from other U.S. states and internationally. As direct emissions from vehicles and energy are reduced over time, an increasingly large fraction of carbon footprints will be embedded in goods and services consumed within the state but produced elsewhere. This underscores the importance of tracking consumption-based emissions over time at state and local levels.

The local abatement potential of each type of strategy (urban infill, conservation, efficiency and renewable energy) for each source of carbon footprints (transportation, housing, food, goods and services) in 2030 is presented in Table 3. Technology solutions from adoption of efficiency and renewable energy account for about $70 \%$ of total abatement, while conservation and urban infill account for $30 \%$. Nearly half of total GHG reductions are from transportation (50.5 $\mathrm{MMTCO}_{2} \mathrm{e}$ ), followed by housing (24 $\left.\mathrm{MMTCO}_{2} \mathrm{e}\right)$, goods and services (16.3 $\mathrm{MMTCO}_{2} \mathrm{e}$ ) and food (9.1 $\mathrm{MMTCO}_{2} \mathrm{e}$ ). Below we discuss potential policies and programs underlying these estimates.

The presence of high carbon footprint neighborhoods in urban cores in Figure 1 may seem to contradict some urban planning principles. Most San Francisco neighborhoods are high density, well connected

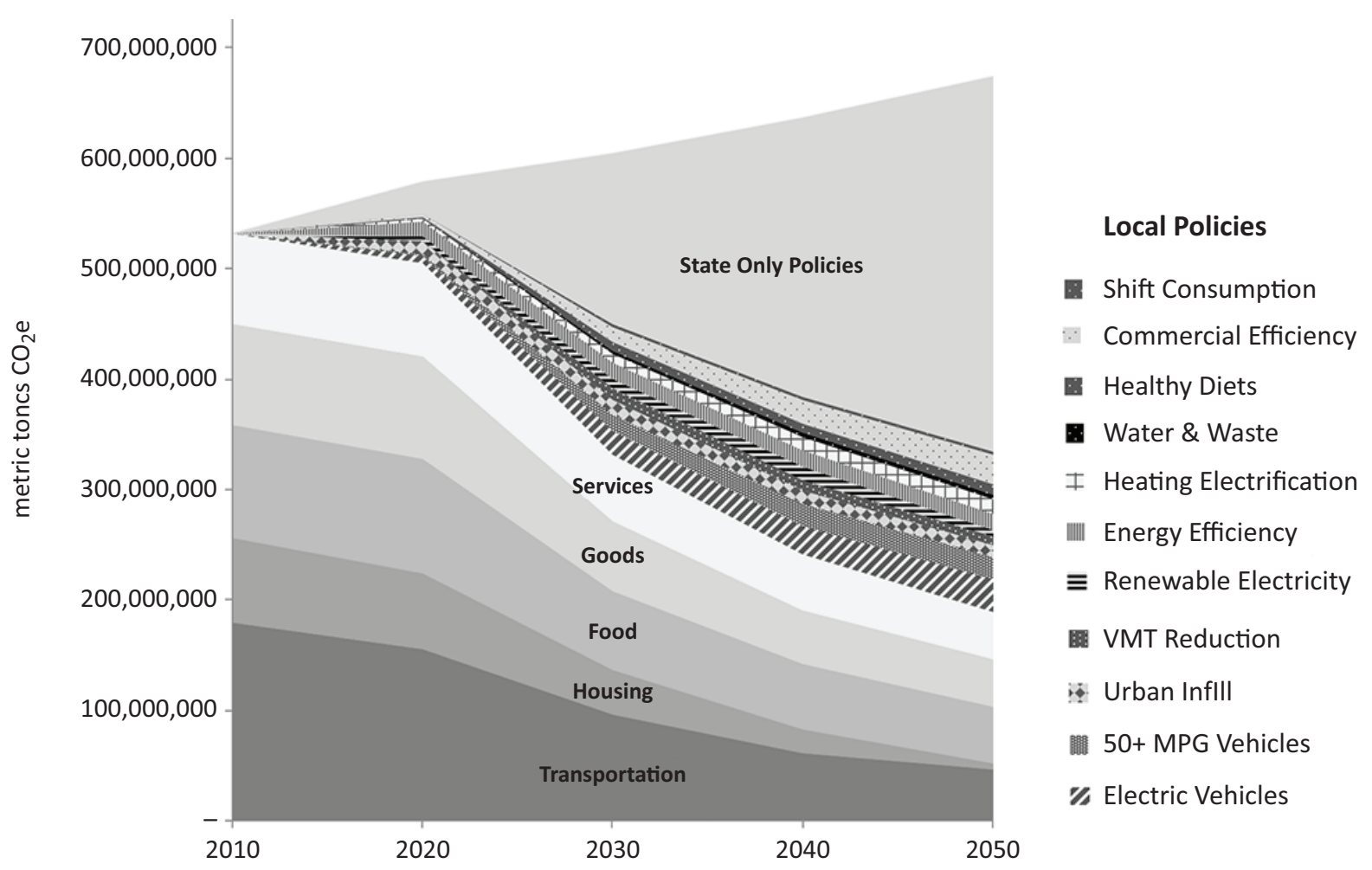

Figure 3. Carbon footprint abatement opportunities from local and state polices for state of California.

Table 3. Local GHG abatement potential in 2030 (million metric tons $\mathrm{CO}_{2} \mathrm{e}$ ) by carbon footprint category and intervention area.

\begin{tabular}{lcccrr}
\hline & Urban Infill & Conservation & Efficiency & Renewable Energy & Total \\
\hline Transportation & 2.5 & 5.4 & 15.6 & 21.1 & 50.5 \\
Energy \& Water & 1.3 & 2.9 & 5.2 & 15.1 & 24.5 \\
Food/Diets & 1.8 & 7.3 & 14.4 & - & 9.1 \\
Goods \& Services & 1.7 & 2.0 & 35.4 & 36.2 & 16.3 \\
\hline TOTAL & 7.3 & 23.3 & 102.2 \\
\hline
\end{tabular}


to transit, jobs, etc., yet many of the city's neighborhoods have higher than average carbon footprints (red colors in Figure 2). Income largely accounts for the discrepancy. Statewide, income explains $62 \%$ of the variation between block groups (Figure 4, right), compared to less than $7 \%$ for population density (Figure 4, left). This follows since expenditures are highly correlated with income, and each dollar spent produces life cycle greenhouse gas emissions that are captured in the consumption-based approach. However, at each income level there is still a wide range of carbon footprints between block groups. At average household income levels of $\$ 60,000$, the range is roughly 30 to $60 \mathrm{tCO}_{2}$ e (Figure 4, right) for California block groups. These differences may be explained by many factors, including urban planning variables such as proximity to transit, jobs, and services, urban form and home characteristics. In a previous study, Jones and Kammen (2014) found that of 32 variables modeled using a similar approach, six explained 93\% of the variation in carbon footprints: vehicle ownership, income, carbon intensity of electricity, home size, household size and population density (in that order).

Following this logic, basing urban infill decisions on the carbon footprints of households at similar income levels may be more effective than basing infill decisions on proxy variables, such as density. To explore this hypothesis, we compared the GHG benefit of adding new housing to all locations over 10,000 persons per square mile vs. locations with below average carbon footprints at all income levels (following the linear fit in Figure 3). Basing urban infill on population density achieves $3 \mathrm{MMTCO}_{2} \mathrm{e}$ abatement in 2030 in California, which is slightly higher than a recent comprehensive estimate of urban infill (Elkind et al., 2017). If, on the other hand, urban infill occurs where household carbon footprints are low relative to other locations with income levels across the state, GHG savings are $7.5 \mathrm{MMTCO}_{2} \mathrm{e}$, three times larger than previous estimates. Using this approach, more locations become good candidates for urban infill, including many high-income neighborhoods in urban cores, such as most of San Francisco, and the wealthy hillside of the East Bay. While these neighborhoods have higher than average carbon footprints, they have lower than average carbon footprints for their income level. Low carbon footprint cities that make housing available at all income levels help share the burden of meeting housing demand, while lessening the impact on the climate across the population. Using our approach, urban infill reduces all aspects of carbon footprints, including $2.5 \mathrm{MtCO}_{2} \mathrm{e}$ from transportation, $1.3 \mathrm{MtCO}_{2} \mathrm{e}$ from energy, $1.8 \mathrm{MtCO}_{2} \mathrm{e}$ from food, and $1.7 \mathrm{MtCO}_{2} \mathrm{e}$ from goods and services statewide. The abatement potential of infill development for transportation and energy has been extensively covered elsewhere (Cervero \& Murakami, 2010; Ewing \& Cervero, 2001). Including food, goods and services roughly doubles this potential in our analysis. Additional work would be needed to determine the true land use potential based on political, economic, social, technological, economic and legal factors.

\subsection{Conservation Strategies}

Conservation requires changing daily activities until those activities become habits. Common strategies include changing environments, for example through choice architecture (Thaler, Sunstein, \& Balz, 2014) or infrastructure investments (e.g., public transit), and changing norms of behavior through feedback, social cues, persuasive messaging and other strategies (Cialdini, 2003; McKenzie-Mohr, 2012; Schultz, Nolan, Cialdini, Goldstein, \& Griskevicius, 2007; Stern et al., 2016). While generally considered less effective than efficiency (Abrahamse et al., 2005), conservation strategies can be an effective "foot-in-the-door" to energy efficiency and re-
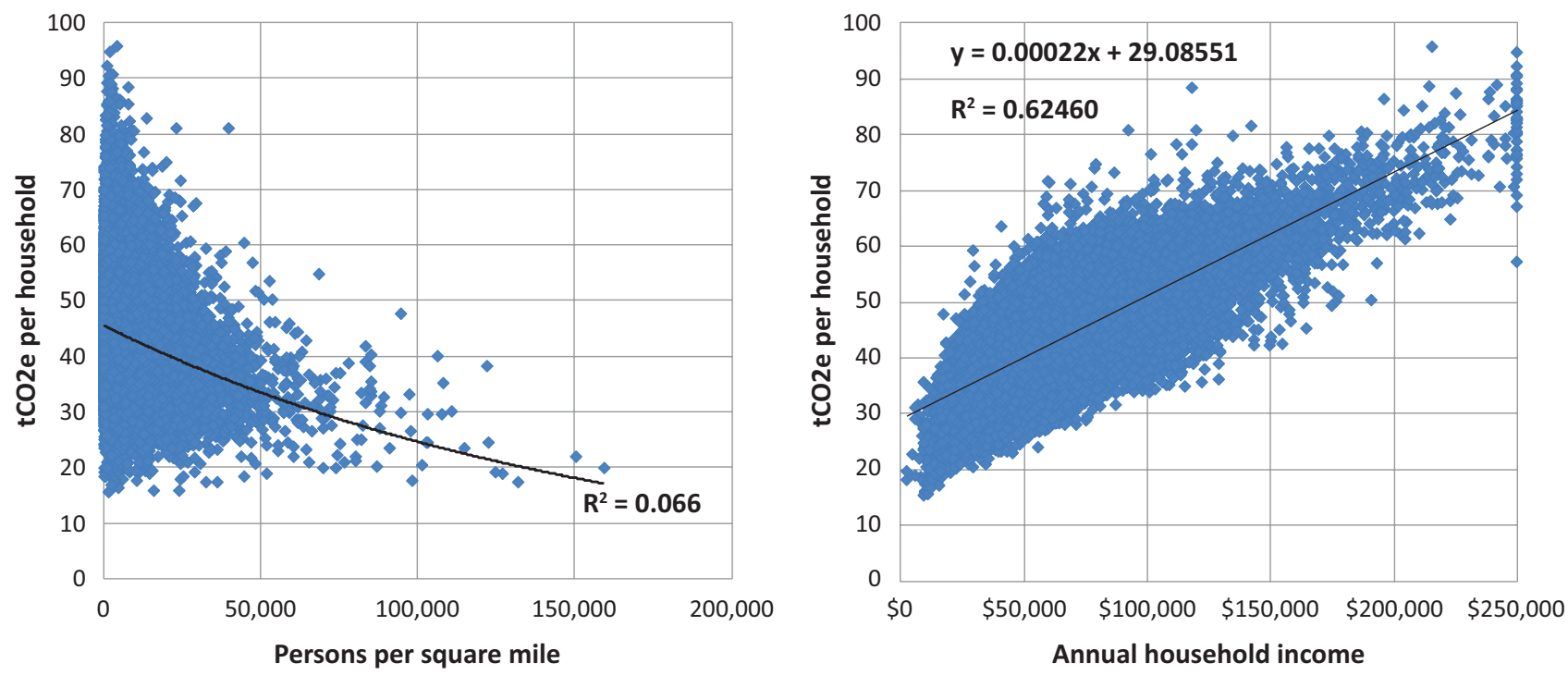

Figure 4. (Left) carbon footprint of Census block groups by population density, and (right) carbon footprints by average annual household income (right-hand figure). 
newable energy purchases that require stronger commitments (Cialdini, 2003). Behavior-based programs can also engage, educate, motivate, and empower (Petersen et al., 2015) communities to take climate action, such as competitions between campuses, businesses and communities (Vine \& Jones, 2016).

Reducing VMT has been a primary objective of urban planning for decades, yet per capita VMT in the state are once again on the rise. New technologies and strategies offer some potential. California's High Speed Rail system is anticipated to reduce statewide GHG emissions by about $1 \%$ when fully implemented (Chester \& Horvath, 2012). Combining this system with new investments in transit, and urban infill will offer low to zero carbon short and long-distance travel. The benefits of transit are greater with increased urban infill, modeled separately. Pay-as-you-drive insurance, lane pricing, gasoline taxes, incentives and other market-based strategies will increasingly put price signals in place. Emerging technologies, including automation, electric vehicles and shared vehicles, hold potential to lower traffic and the use of single occupant vehicles. A $10 \%$ reduction in VMT would reduce $5.4 \mathrm{MMTCO}_{2} \mathrm{e}$ in 2030, even with aggressive improvements in vehicle fuel economy and electrification.

Conserving energy holds less potential in California than in many other locations due to increasingly low carbon-intensity of electricity and relatively mild climate. Only $10 \%$ of household carbon footprints are from electricity and heating fuels combined statewide, and less than $5 \%$ in mild coastal areas, such as the San Francisco Bay Area. Full adoption of energy conservation behaviors (curtailment) would reduce $2.4 \mathrm{MMTCO}_{2} \mathrm{e}$ in 2030 , with considerably more savings from energy efficiency (below).

Food accounted for nearly $20 \%$ of GHG emissions from a consumption perspective in 2010 and we project it will be the largest source of carbon footprints by 2050, even with aggressive efforts to reduce methane from the dairy and cattle industries and other improvements. The average American household spends $\$ 7,000$ per year on food (over $10 \%$ of gross annual income), and each dollar produces about $1 \mathrm{~kg}$. $\mathrm{CO}_{2} \mathrm{e}$, on average, throughout supply chains (Suh, 2009). Shifting $12 \%$ of Californians to healthy, low-carbon diets (with $50 \%$ fewer calories from meat, dairy, and processed foods) would reduce 7.6 $\mathrm{MMTCO}_{2} \mathrm{e}$ in 2030. School lunch programs, dietary guidelines, urban agriculture, education, improved food access, reducing food waste, partnerships with restaurants and supermarkets, and product labeling are just a few of the ideas that have been initiated to address food. Commensurate levels of funding and engagement are necessary to address food systems.

Household consumption is the target of polices and campaigns to reduce, reuse and recycle goods and materials. Since life cycle emission factors of manufactured goods already include benefits of recycled materials, we have not included the GHG potential of additional recycling efforts; however, the marginal benefit of recycling for communities is still large. Another possible strategy is to shift consumption by promoting local services. On average, services require $\sim 500$ grams $\mathrm{CO}_{2}$ e per U.S. dollar versus $\sim 800$ grams for goods produced in the U.S. (Suh, 2009), while California businesses that use local low carbon sources of energy likely produce fewer emissions (Reich-Weiser, 2010). Shifting 15\% of expenditures from goods to services would reduce $2 \mathrm{MMTCO}_{2}$ e statewide. Local governments can also engage local businesses in conservation measures; we include total savings from the commercial sector into efficiency strategies below.

\subsection{Efficiency Strategies}

Efficiency strategies involve encouraging energy efficient, or efficiently-produced, goods and services, usually at a single point in time. Policies include incentives, labeling, codes, standards and behavior-based programs. While frequently applied to motor vehicles and energy (buildings and appliances), the same strategies are increasingly being applied to encourage low-carbon production and consumption of food, goods and services (Hertwich et al., 2010).

Improving the fuel economy of motor vehicles is the single largest source of emission reductions, savings nearly $15.6 \mathrm{MMTCO}_{2}$ e by 2030 . We have only modeled abatement from fuel economy standards for internal combustion engine (ICE) vehicles, but policymakers can begin encouraging more efficient electric and alternative fuel vehicles as well. The most fuel-efficient ICE vehicles consume $30 \%$ less fuel than inefficient ICE's; conversely, the most efficient electric vehicles consume $50 \%$ fewer kWh than the least efficient electric vehicles (U.S. Department of Energy, 2010). Efficient motorcycles and electric bicycles should also be considered in a low-carbon motorized vehicle fleet.

California state policy mandates that all new residential buildings be zero net energy (ZNE) by 2025 and the state seeks $40 \%$ efficiency gains in existing buildings by 2030. Achieving these targets will require substantial collaboration with local governments. We estimate that total statewide savings potential of $9.2 \mathrm{MMTCO}_{2}$ e with $57 \%$ at least partially within local control. It is important to note that energy efficiency is a short to medium-term strategy. Once $100 \%$ heating electrification is achieved and all electricity is produced from renewable sources, energy efficiency will no longer lead to reductions in household GHG emissions.

We have not modeled any GHG benefits for choosing efficiently-produced foods. Despite strong interest in local and organic food, food miles tend to be only $5-10 \%$ of emissions from most foods (Weber \& Matthews, 2008) and there is wide is variation in the carbon intensity of food production (Cooper, Butler, \& Leifert, 2011).

Reducing emissions in the commercial sector by $15 \%$ saves $14.4 \mathrm{MMTCO}_{2} \mathrm{e}$ in 2030 . Local governments can use their convening power to build coalitions to support local green businesses. California has 
a robust network of green business certification programs, as well as statewide awards and recognition (http://coolcalifornia.org). While industrial emissions are managed largely by state policy, including cap-and-trade, local governments have considerable influence over commercial emissions.

\subsection{Renewable Energy and Decarbonizing Fuels}

Decarbonizing fuels has historically been the last option in the loading order of energy policies (Waide \& Buchner, 2008); however, this is changing as the cost of renewable energy has decreased. Fully electric homes, combined with electric vehicles and renewable electricity offer a large and quick, albeit still relatively costly, abatement opportunity.

California has set a target of 4.2 million electric vehicles by 2030, a jump from just 200,000 full plug-in electric vehicles in 2010. To-date, incentives have been insufficient to drive widescale adoption of EVs even as purchase prices and leases have come down. Local governments can encourage the use of electric vehicles by adding charging stations, offering free parking or other incentives, equipping new homes with charging infrastructure, fleet purchases, and public engagement campaigns. As these vehicles become more popular there may also be a "Prius effect" (Sexton \& Sexton, 2011), with social norms encouraging more adoption. Encouraging
$10 \%$ adoption of electric vehicles by 2030 (less than 2 million vehicles) would reduce $18 \mathrm{MMTCO}_{2}$ e statewide.

By 2050, virtually all electricity must come from renewable sources in order to meet California's climate targets (Wei et al., 2013; Williams, et al., 2012). As this transition happens, the GHG abatement potential of energy efficiency and conservation will decrease relative to switching from gas to electricity for most home end uses. California's Draft Scoping Plan does not include heating electrification, but recent analysis demonstrates this policy would not add considerably to the cost of the portfolio of policy measures currently considered in the plan (Raghavan, Wei, \& Kammen, 2017). Solar photovoltaic and local renewable energy offer considerable potential for communities to take charge of energy choices. Converting $30 \%$ of homes from natural gas to electricity would save $7.7 \mathrm{MMTCO}_{2}$ e by 2030 . Increasing renewable energy by just $10 \%$ would also reduce over $7 \mathrm{MMTCO}_{2} \mathrm{e}$ in 2030.

\section{The Carbon Footprint Abatement Potential of California Cities}

The mitigation potential of jurisdictions depends largely on the size and composition of household carbon footprints. Figure 5 compares local abatement potential of three very different California cities, each with about 100,000 population: El Monte, Berkeley and Tracy. El

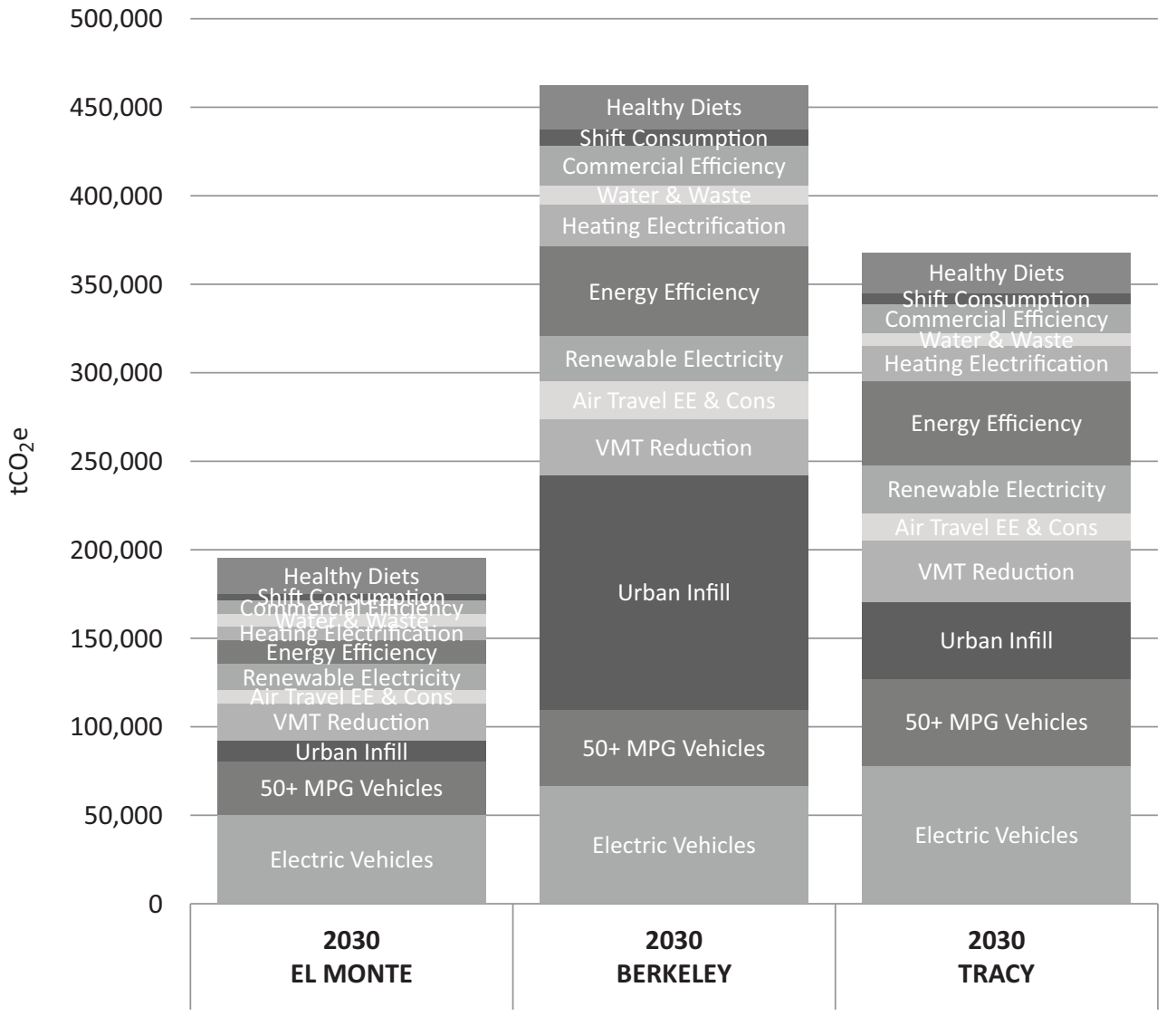

Figure 5. Carbon footprint abatement opportunities for selected cities with $\sim 100,000$ population. 
Monte (1.25 $\left.\mathrm{MMtCO}_{2} \mathrm{e}\right)$ is a relatively low income, low carbon footprint community in Los Angeles County. While population exceeds 101,000 , household size is higher than average, translating to relatively higher emissions per household from food, but lower carbon footprint overall. Urban infill potential (using our approach of only moving households with similar income) is low since low income households elsewhere in California also have low carbon footprints. The city of Berkeley (1.6 $\left.\mathrm{MMtCO}_{2} \mathrm{e}\right)$, with fewer residents $(\sim 92,0000)$ has more than double the abatement opportunity, with large potential from urban infill (over $120,000 \mathrm{tCO}_{2} \mathrm{e}$ in 2030), energy (mainly reducing, and eventually eliminating, natural gas) and efficiency in the commercial sector. The city of Tracy (1.9 $\mathrm{MMtCO}_{2} \mathrm{e}$ with 106,000 people), a distant Bay Area suburb, holds the highest abatement potential from electric and high efficiency vehicles and renewable energy. While these cities are somewhat extreme cases, they demonstrate the range in the size and composition of mitigation opportunities for similarly-sized cities.
Large differences between carbon footprints of neighborhoods present important environmental justice concerns. Those who are least responsible for emissions are frequently the most exposed to harmful effects of pollution. However, under our deep carbon footprint abatement scenario, which is in line with policies to meet California's climate targets for 2030 and 2050, these differences are dramatically reduced over time. Deep GHG abatement reduces air pollution as well as disparities in GHG responsibility (carbon footprints). Figure 6 displays average household carbon footprints in San Diego County under our climate target compliance scenario. By 2050, the average household carbon footprint in San Diego County drops from 44.1 to $12.8 \mathrm{tCO}_{2}$ e per household, with much smaller differences between neighborhoods: standard deviation $=2.4$ in 2050, compared to 9.7 in 2010. If California meets its climate targets, large disparities in carbon footprints will essentially disappear with important co-benefits of reduced pollution in vulnerable communities.

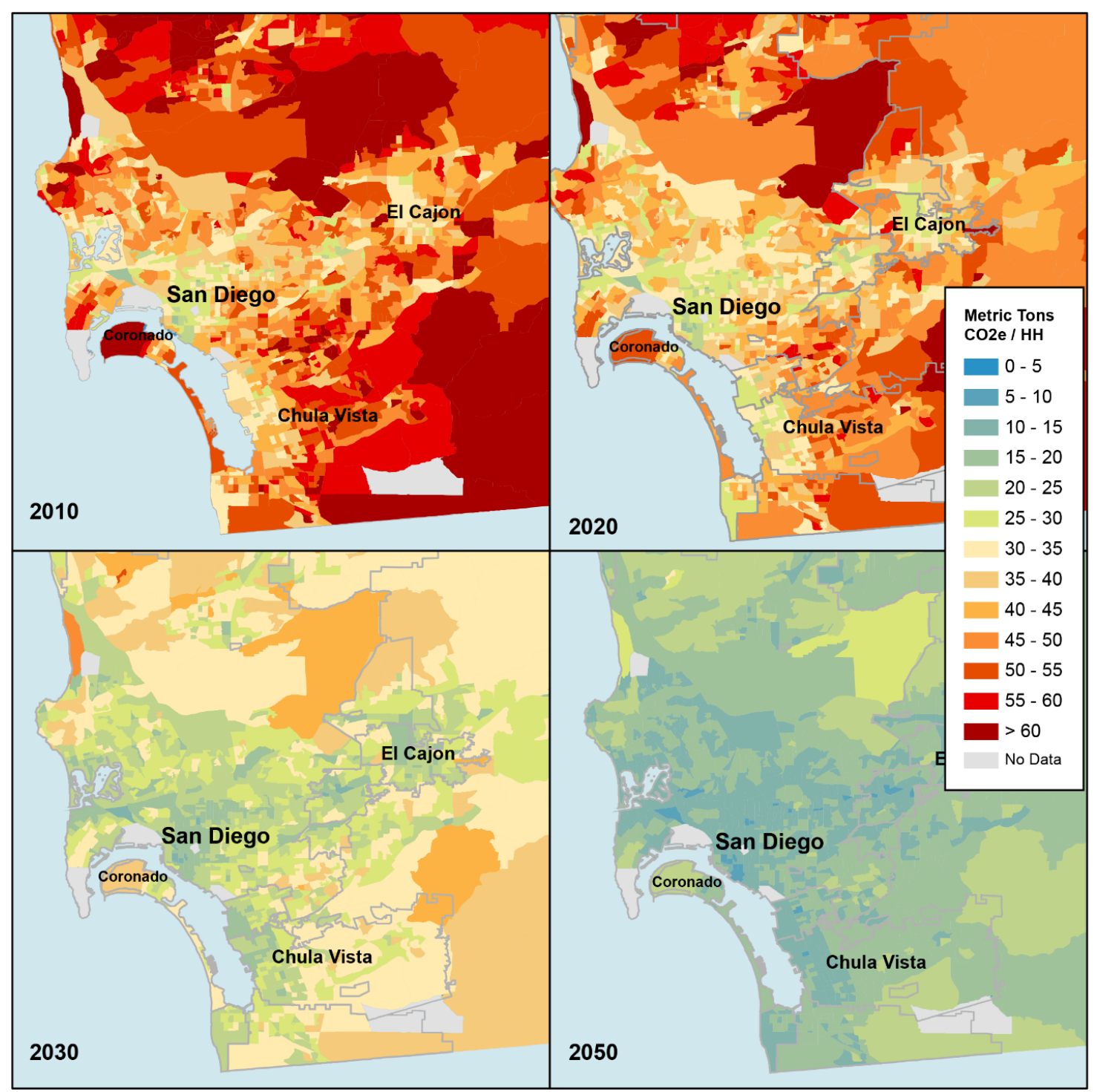

Figure 6. Average household carbon footprints of San Diego County neighborhoods under CA climate targets. 


\section{Uncertainty and Limitations}

Like any model, our results must be observed within the context of the assumptions we have made. Much of our work on carbon footprint modeling has been extensively peer reviewed in previous studies (Jones \& Kammen, 2011, 2014, 2015). Potential sources of uncertainty include measurement error (e.g., in surveys used), aggregation error (combining disparate types of products in a single product category), modeling error (e.g., assuming linear models, and goodness of fit), parameter errors (e.g., outdated datasets), and linguistic imprecision, among others. The newest feature of our model is the projection to the year 2050 based on assumptions about potential adoption rates and the split between state only and 'local' policy intervention areas. Adoption rates were chosen to align with previous studies that describe what would be needed to meet California's aggressive GHG targets. This is in no way a prediction of future emissions, but rather a scenario for deep GHG abatement. Free interactive online tools are available for readers interested in developing their own scenarios for any California city or county (http://coolclimate.org/scenarios-california).

The consumption-based inventory approach also has inherent limitations, even if modeled accurately. Actual expenditures on food, goods and services are only known at the scale of large metropolitan areas, and not individual cities or neighborhoods within cities; these are estimated based on household size and income. Thus, there may be important differences between locations, and changes in spending habits over time are only reflected at metropolitan scales. Furthermore, we assume that consumers purchase average quality goods, with similar emissions per dollar of expenditure. This is particularly problematic for high income neighborhoods that are more likely to purchase luxury goods at relatively high cost for similar products. Furthermore, consumptionbased inventories, such as ours, may only be updated every five years or more due to data availability and resources. It may therefore be difficult, or even impossible, for cities to track full consumption-based emissions regularly over time without a costly survey approach. While cities may have difficulty tracking emissions over time, households can do this quite effectively using a household carbon footprint calculator, such as ours (http://coolclimate.org/calculator). The real value of a consumption-based inventory is the ability to engage individuals and households in climate action. It should thus serve as a complement, and not a replacement, to a traditional GHG inventory.

\section{Conclusion}

This study developed a consumption-based GHG emissions inventory of all California neighborhoods, cities and counties, with projections to the year 2050 based on a deep carbon footprint abatement scenario. Statewide, GHG reductions consistent with meeting California's ag- gressive GHG targets would require local involvement in at least $35 \%$ of needed abatement. Urban planning, conservation, energy efficiency and renewable energy all require extensive local participation. A combination of state and local policies consistent with meeting California's production-based target of $80 \%$ reduction by 2050 would reduce consumption-based emissions by an estimated $65 \%$ by 2050 . Increasingly, a larger share of emissions will be exported outside of California. We project food will become the largest source of carbon footprints by 2050; shifting attention to promoting healthy, lowcarbon diets is becoming increasingly important from a consumption perspective.

Our analysis of California carbon footprints leads to a number of priorities specific to California locations throughout the state (e.g., vehicle and heating electrification, renewable energy, urban infill, changing diets), some of which would be different for other regions with different climates, amounts of driving, incomes, and physical forms. Regardless of place-based priorities, accounting for consumption and modeling policy outcomes can help local governments concentrate on implementing the most promising policies and programs.

The results also support different GHG reduction priorities for suburban and urban areas. Technologyoriented strategies such as all-electric homes and cars appear desirable for affluent suburban jurisdictions with large houses, large rooftops, and long private-vehicle commute trips (e.g., the city of Tracy). Households in these locations often have the ability to generate photovoltaic electricity which-coupled with conservation and efficiency improvements-could potentially meet their energy demand for both home heating/cooling and transportation. Households in less-affluent, high-density urban neighborhoods (e.g., El Monte) may have lower energy consumption as well as less financial ability or rooftop space to generate photovoltaic energy. Since a larger proportion of their emissions come from household consumption, they appear be better candidates for campaigns to promote healthy diets and sustainable consumption. Mixed income urban core cities (e.g., Berkeley) hold the most potential for urban infill, with statewide GHG benefits.

Reducing consumption-related GHG emissions will almost certainly require changing behavior. Neighborhood-scale GHG emissions data can help target many of these efforts. Comparisons of household carbon footprints may be particularly useful at neighborhood scale where differences are the largest and households can compare their own carbon footprints (http://coolclimate.org/calculator) with neighborhood averages (http://coolclimate.org/maps-2050).

We recognize that in most cases political support, institutions, and economics would need to evolve in order to make such actions possible. To achieve full GHG abatement, local governments will need to think and act in new ways: as conveners, advocates and collaborators in community-wide engagement in climate action. Sev- 
eral cities in California are already moving along this path, serving as models for similar communities beyond California's borders.

Consumption-based, neighborhood-specific GHG footprint mapping and planning has the potential to usher in a new era of climate change planning, one which addresses emissions more comprehensively and more locally, and engages household fully in their climate commitments. The highly scalable method presented here allows cities to get started immediately, without producing expensive inventories of their own. This same method could be applied to all U.S. locations and other countries, helping to identify the most promising policies to drive low carbon economies globally.

Consumption-based, high geospatial resolution GHG inventories and planning tools appear to have some important advantages over other inventory methods. They give local and regional officials the most complete accounting of their residents' carbon footprints and provide potential intervention strategies down to neighborhood scale. Supplemental carbon footprint calculators can engage households directly in tracking and reducing their carbon footprints over time. For California, our inventory, maps, calculator and policy scenario tools can support prioritization of GHG policies for local governments throughout the state.

\section{Supporting Online Tools and Materials}

Supporting tools and data are available for free access on the project website: http://coolclimate.org.

- A results spreadsheet for all California cities and counties: http://coolclimate.org/data;

- Interactive online map for any neighborhood for years 2010-2050: http://coolclimate.org/maps2050;

- Carbon footprint scenario tool for all California cities and counties: http://coolclimate.org/scen arios-california;

- CoolClimate Calculator, an online tool allowing users to compare their carbon footprints to similar households and create customized climate action plans: http://coolclimate.org/calculator.

\section{Acknowledgements}

The authors are grateful for funding from CoolClimate Network members, the California High Speed Rail Authority and the Bay Area Air Quality Management District. All maps for this project were prepared by Brent Levin. Ben Gould developed the online policy tool. The authors also thank several anonymous reviewers and staff from local municipal governments who provided useful feedback. Publication made possible in part by support from the Berkeley Research Impact Initiative (BRII), sponsored by the UC Berkeley Library.

\section{Conflicts of Interest}

The authors declare no conflicts of interest.

\section{References}

Abrahamse, W., \& Steg, L. (2013). Social influence approaches to encourage resource conservation: A meta-analysis. Global Environmental Change, 23(6), 1773-1785.

Abrahamse, W., Steg, L., Vlek, C., \& Rothengatter, T. (2005). A review of intervention studies aimed at household energy conservation. Journal of Environmental Psychology, 25(3), 273-291.

Adnan, M. N., Safeer, R., \& Rashid, A. (2018). Consumption based approach of carbon footprint analysis in urban slum and non-slum areas of Rawalpindi. Habitat International, 73, 16-24.

BAAQMD. (2017). Spare the air, cool the climate: A blueprint for clean air and climate protection in the Bay Area. Bay Area Air Quality Management District. Retrieved from http://www.baaqmd.gov/ /media/ files/planning-and-research/plans/2017-clean-air-plan /attachment-a_-proposed-final-cap-vol-1-pdf.pdf?la $=$ en

Barrett, J., Minx, J. C., \& Paul, A. (2007). Towards a low footprint Scotland: Living well, within our ecological limits (Working Paper). York: Stockholm Environment Institute. Retrieved from https://opus4.kobv. de/opus4-hsog/frontdoor/index/index/docld/1920

Bassett, E., \& Shandas, V. (2010). Innovation and climate action planning. Journal of the American Planning Association, 76(4), 435-450.

Bedsworth, L. W., \& Hanak, E. (2013). Climate policy at the local level: Insights from California. Global Environmental Change, 23(3), 664-677.

Boswell, M. R., Greve, A. I., \& Seale, T. L. (2012). Local climate action planning. Washington DC: Island Press.

Bulkeley, H. A., Broto, V. C., \& Edwards, G. A. (2014). An urban politics of climate change: Experimentation and the governing of socio-technical transitions. New York, NY: Routledge.

Bureau of Labor Statistics. (2013). Consumer expenditures survey. Bureau of Labor Statistics. Retrieved from http://www.bls.gov/cex

C2ER. (2014). Cost of living index. The Council for Community and Economic Research. Retrieved from http://www.coli.org

Cervero, R., \& Murakami, J. (2010). Effects of built environments on vehicle miles traveled: Evidence from 370 US urbanized areas. Environment and Planning A, 42(2), 400-418.

Chavez, A., \& Ramaswami, A. (2013). Articulating a transboundary infrastructure supply chain greenhouse gas emission footprint for cities: Mathematical relationships and policy relevance. Energy Policy, 54, 376-384. 
Chester, M., \& Horvath, A. (2012). High-speed rail with emerging automobiles and aircraft can reduce environmental impacts in California's future. Environmental Research Letters, 7(3), 034012.

Cialdini, R. B. (2003). Crafting normative messages to protect the environment. Current Directions in Psychological Science, 12(4), 105-109.

Cooper, J. M., Butler, G., \& Leifert, C. (2011). Life cycle analysis of greenhouse gas emissions from organic and conventional food production systems, with and without bio-energy options. NJAS - Wageningen Journal of Life Sciences, 58(3), 185-192.

Delmas, M. A., Fischlein, M., \& Asensio, O. I. (2013). Information strategies and energy conservation behavior: A meta-analysis of experimental studies from 1975 to 2012. Energy Policy, 61, 729-739.

Dickinson, J., Khan, J., \& Amar, M. (2013). City of New York: Inventory of New York city greenhouse gas emissions. New York, NY: Mayor's Office of Long-Term Planning and Sustainability. Retrieved from https:// www1.nyc.gov/assets/sustainability/downloads/pdf /publications/NYC_GHG_Inventory_2013.pdf

Dietz, T., Gardner, G. T., Gilligan, J., Stern, P. C., \& Vandenbergh, M. P. (2009). Household actions can provide a behavioral wedge to rapidly reduce US carbon emissions. Proceedings of the National Academy of Sciences, 106(44), 18452-18456.

Elkind, E. N., Galante, C., Decker, N., Chapple, K., Martin, A., \& Hanson, M. (2017). Right type right place: Assessing the environmental and economic impacts of infill residential development through 2030. Center for Law, Energy \& the Environment Publications, 40. Retrieved from http://scholarship.law.berkeley.edu/ cleepubs $/ 40$

Erickson, P., Allaway, D., Lazarus, M., \& Stanton, E. A. (2012). A consumption-based GHG inventory for the U.S. state of Oregon. Environmental Science \& Technology, 46(7), 3679-3686.

Erickson, P., Chandler, C., \& Lazarus, M. (2012). Reducing greenhouse gas emissions associated with consumption: A methodology for scenario analysis. Stockholm: Stockholm Environment Institute. Retrieved from http://www.academia.edu/download/43267324/Re ducing_Greenhouse_Gas_Emissions_Associ2016030 2-28865-3dmcd0.pdf

Ewing, R., \& Cervero, R. (2001). Travel and the built environment: A synthesis. Transportation Research Record: Journal of the Transportation Research Board, 1780(1), 87-114.

Feng, K., Hubacek, K., Sun, L., \& Liu, Z. (2014). Consumption-based $\mathrm{CO} 2$ accounting of China's megacities: The case of Beijing, Tianjin, Shanghai and Chongqing. Ecological Indicators, 47, 26-31.

Greenblatt, J. B. (2015). Modeling California policy impacts on greenhouse gas emissions. Energy Policy, 78, 158-172.

Hertwich, E., van der Voet, E., Suh, S., Tukker, A., Huijbregts, M., Kazmierczyk, P., ... Moriguchi, Y. (2010).
Assessing the environmental impacts of consumption and production: Priority products and materials. United National Environment Programme. Retrieved from http://www.unep.fr/shared/publications/pdf/ DTIx1262xPA-PriorityProductsAndMaterials_Report. pdf

Hillman, T., \& Ramaswami, A. (2010). Greenhouse gas emission footprints and energy use benchmarks for eight U.S. cities. Environmental Science \& Technology, 44(6), 1902-1910.

ICLEI. (2012). U.S. community protocol for accounting and reporting of greenhouse gas emissions. ICLEI: Local Governments for Sustainability. Retrieved from http://www.icleiusa.org/tools/ghg-protocol/ community-protocol/us-community-protocol-for-ac counting-and-reporting-of-greenhouse-gas-emissions

IPCC. (2014). IPCC fifth assessment report. IPCC: Intergovernmental Panel on Climate Change. Retrieved from http://www.ipcc.ch/report/ar5/

Ivanova, D., Vita, G., Steen-Olsen, K., Stadler, K., Melo, P. C., Wood, R., \& Hertwich, E. G. (2017). Mapping the carbon footprint of EU regions. Environmental Research Letters, 12(5), 054013.

Jones, C., \& Kammen, D. M. (2011). Quantifying carbon footprint reduction opportunities for U.S. households and communities. Environmental Science \& Technology, 45(9), 4088-4095.

Jones, C., \& Kammen, D. M. (2014). Spatial distribution of U.S. household carbon footprints reveals suburbanization undermines greenhouse gas benefits of urban population density. Environmental Science \& Technology, 48(2), 895-902.

Jones, C. M., \& Kammen, D. M. (2015). A consumptionbased greenhouse gas inventory of San Francisco bay area neighborhoods, cities and counties: Prioritizing climate action for different locations. Berkeley, CA: University of California. Retrieved from https:// escholarship.org/uc/item/2sn7m83z

Jones, C. M., \& Kammen, D. M. (2018). Pathway analysis to accelerate California's low carbon economy. Unpublished manuscript.

Larsen, H. N., \& Hertwich, E. G. (2009). The case for consumption-based accounting of greenhouse gas emissions to promote local climate action. Environmental Science \& Policy, 12(7), 791-798.

Lazarus, M., Chandler, C., \& Erickson, P. (2013). A core framework and scenario for deep GHG reductions at the city scale. Energy Policy, 57, 563-574.

Lenzen, M., \& Peters, G. M. (2010). How city dwellers affect their resource hinterland. Journal of Industrial Ecology, 14(1), 73-90.

McKenzie-Mohr, D. (2012). Fostering sustainable behavior: Community-based social marketing. Retrieved from http://www.cbsm.com/pages/guide/preface/

Mi, Z., Zhang, Y., Guan, D., Shan, Y., Liu, Z., Cong, R., ... Wei, Y.-M. (2016). Consumption-based emission accounting for Chinese cities. Applied Energy, 184, 1073-1081. 
Minx, J., Baiocchi, G., Wiedmann, T., Barrett, J., Creutzig, F., Feng, K., ... Hubacek, K. (2013). Carbon footprints of cities and other human settlements in the UK. Environmental Research Letters, 8(3), 035039.

Oak Ridge National Laboratory. (2013). 2017 summary statistics for demographic characteristics and travel. National Household Travel Survey 2013. Retrieved from http://nhts.ornl.gov

Petersen, J. E., Frantz, C. M., Shammin, M. R., Yanisch, T. M., Tincknell, E., \& Myers, N. (2015). Electricity and water conservation on college and university campuses in response to national competitions among dormitories: Quantifying relationships between behavior, conservation strategies and psychological metrics. PLOS ONE, 10(12), e0144070.

Raghavan, S. V., Wei, M., \& Kammen, D. M. (2017). Scenarios to decarbonize residential water heating in California. Energy Policy, 109, 441-451.

Ramaswami, A., \& Chavez, A. (2013). What metrics best reflect the energy and carbon intensity of cities? Insights from theory and modeling of 20 US cities. Environmental Research Letters, 8(3), 035011.

Raupach, M. R., Marland, G., Ciais, P., Quéré, C. L., Canadell, J. G., Klepper, G., \& Field, C. B. (2007). Global and regional drivers of accelerating $\mathrm{CO}_{2}$ emissions. Proceedings of the National Academy of Sciences, 104(24), 10288-10293.

Reich-Weiser, C. L. (2010). Decision-making to reduce manufacturing greenhouse gas emissions (Ph.D. dissertation). University of California, Berkeley, CA, Retrieved from http://search.proquest.com/docview /1095574198/abstract/B02625E7D10C444BPQ/1

Schultz, P. W., Nolan, J. M., Cialdini, R. B., Goldstein, N. J., \& Griskevicius, V. (2007). The constructive, destructive, and reconstructive power of social norms. Psychological Science, 18(5), 429-434.

Sexton, S. E., \& Sexton, A. L. (2011). Conspicuous conservation: The Prius effect and willingness to pay for environmental bona fides (Working Paper). Berkeley, CA: University of California. Retrieved from https://works.bepress.com/sexton/11/download

Stern, P. C., Janda, K. B., Brown, M. A., Steg, L., Vine, E. L., \& Lutzenhiser, L. (2016). Opportunities and insights for reducing fossil fuel consumption by households and organizations. Nature Energy, 1, 16043.

Sudmant, A., Gouldson, A., Millward-Hopkins, J., Scott, K., \& Barrett, J. (2017). Producer cities and consumer cities: Using production-and consumption-based carbon accounts to guide climate action in China, the UK, and the US. Journal of Cleaner Production, 176,
654-662.

Suh, S. (2009). Developing the sectoral environmental database for input-output analysis: Comprehensive environmental data archive of the US. Handbook of Input-Output Economics in Industrial Ecology, 17(4), 689-712.

Thaler, R. H., Sunstein, C. R., \& Balz, J. P. (2014). Choice Architecture, In Shafir, Elgar, ed. The behavioral foundations of public policy, Ch. 25. Rochester, NY: Social Science Research Network. Retrieved from https://papers.ssrn.com/abstract $=2536504$

U.S. Department of Energy. (2010). Fuel Economy. Fueleconomy. Retrieved from http://fueleconomy.gov

U.S. Energy Information Administration. (2009). Residential energy consumption survey, 2009. U.S. Energy Information Administration. Retrieved from https:// www.eia.gov/consumption/residential/data/2009

USDA. (2015). Nutrient data: USDA national nutrient database for standard reference. United States Department of Agriculture: Agricultural Research Service. Retrieved from http://www.ars.usda.gov/ Services $/$ docs. htm ?docid $=8964$

Vine, E. L., \& Jones, C. M. (2016). Competition, carbon, and conservation: Assessing the energy savings potential of energy efficiency competitions. Energy Research \& Social Science, 19, 158-176.

Waide, P., \& Buchner, B. (2008). Utility energy efficiency schemes: savings obligations and trading. Energy Efficiency, 1(4), 297-311.

Weber, C., \& Matthews, S. (2008). Food-miles and the relative climate impacts of food choices in the United States. Environmental Science and Technology, 42(10), 3508-3513.

Wei, M., Nelson, J. H., Greenblatt, J. B., Mileva, A., Johnston, J., Ting, M., ... Kammen, D. M. (2013). Deep carbon reductions in California require electrification and integration across economic sectors. Environmental Research Letters, 8(1), 014038.

Wheeler, S. M. (2012). Climate change and social ecology: A new perspective on the climate challenge. New York, NY: Routledge.

Wiedmann, T. O., Chen, G., \& Barrett, J. (2015). The concept of city carbon maps: A case study of Melbourne, Australia. Journal of Industrial Ecology, 20(4), 676-691.

Williams, J. H., DeBenedictis, A., Ghanadan, R., Mahone, A., Moore, J., Morrow, W. R. III., ... Torn, M. S. (2012). The technology path to deep greenhouse gas emissions cuts by 2050: The pivotal role of electricity. Science, 335(6064), 53-59. 


\section{About the Authors}

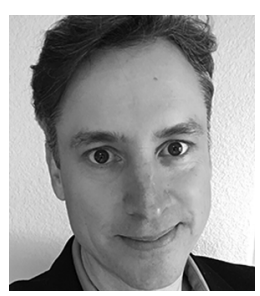

Christopher M. Jones is Director of the CoolClimate Network, an applied research consortium at the University of California, Berkeley.

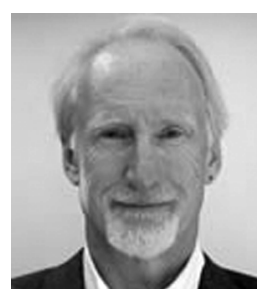

Stephen M. Wheeler is a Professor in the Department of Human Ecology at the University of California, Davis.

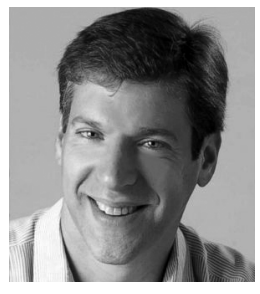

Daniel M. Kammen is Professor and Chair of the Energy and Resources Group, Professor in the Goldman School of Public Policy and in the Department of Nuclear Engineering, as well as Director of the Renewable and Appropriate Laboratory at the University of California, Berkeley. 